\title{
Quality Management Through ISO Certification And Quality Costs Reporting: A Study Of Bahraini Companies
}

Sayel Ramadhan (E-Mail: sayel@buss.uob.bh), University of Bahrain Raja Bucheery, University of Bahrain

\begin{abstract}
This study investigates quality management by Bahraini companies through qualifying for ISO certification and measurement and reporting of cost of quality. Its main purpose is to examine the motivation behind quality certification and the extent to which Bahraini firms measure and report quality costs. A sample of 100 companies was selected at random from the Ministry of Commerce Directory. A mail questionnaire was developed and distributed to the entire sample. Eighty one companies responded to the questionnaire; a response rate of (81\%) which is considered appropriate for this type of study. Of the (81) firms, (47) are ISO certified and the dominant reasons for quality certification are: to improve the firm's competitive advantage; to respond to customer demands; and to reduce costs. Cost of quality reporting is adopted by (40) firms (49.4\%) of the respondents to the question; (22) companies indicated that they plan to implement cost of quality reporting; and the remaining (14) companies have no plans to implement it. The most important uses of a quality cost report are: product cost information; quality cost planning; and targeting areas for process and product improvement. The main reason for not measuring quality costs are: "the extensive use of non-financial measures" and "quality is part of the firm's culture".
\end{abstract}

\section{INTRODUCTION}

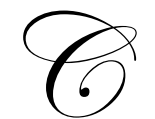

ustomers are demanding increasing levels of quality of the products provided to them. They expect higher levels of quality and are becoming intolerant of poor quality. To satisfy customers and to be competitive, managers need to find cost-effective ways to continuously improve the quality of their products. The effect of quality management in any organization is directly proportionate to profit and customer satisfaction. A good quality management system will reduce deficiencies which will bring down the cost and increase customer satisfaction. Organisations depend on their customers and therefore should understand current and future needs, meet their requirements and strive to exceed customer expectations. The challenge for an organization that seeks to become a total quality organization is to achieve a zero gap between customer expectations and performance or to deliver a product or service that exceeds customer expectations. Also, to ensure that their suppliers deliver highquality products at competitive prices, major purchasers (e.g., General Electric in USA) require their suppliers to obtain quality certification.

The International Organization for Standardization (ISO) issued a set of international standards for quality management adopted by more than (90) countries. Therefore, many firms have taken the initiative of obtaining quality certification for the purpose of sustaining competitive advantage and improve their financial performance. In addition, costs accountants, especially in manufacturing firms, started measuring the quality costs on a regular basis. This paper examines the extent to which Bahraini companies obtained ISO certification; the motivation behind quality certification; and the factors which encourage firms to implement cost of quality reporting. The next section of the paper reviews the existing literature on cost of quality. Section three discusses the research method. Section four presents the findings of the study. The last section concludes the study, highlights its limitations, and suggests directions for future research. 


\section{IMPORTANCE OF THE STUDY}

The study has the potential to make a contribution to the management accounting literature because it is reporting on the experiences of companies in non-Western government dominated economy adopting practices developed in industrialized countries. In addition, it is interesting to know the current status of Bahraini firms regarding ISO certification and cost of quality reporting and use. The results should help readers understand what motivates (local and global factors) Bahraini companies to seek ISO certification and measure and report quality costs.

\section{DESCRIPTION OF BAHRAINI CULTURE}

Bahrain is a small Island in the Gulf region and is situated about 15 miles from the east coast of Saudi Arabia. The area of Bahrain is about 600 square kilometers and the population is about 600000 . Bahrain experienced a remarkable economic growth following the 1970 oil boom. Its major industries include oil refining, aluminum smelting, ships repair, and construction work. This is in addition to offshore banking and other financial services. In 2001, the gross domestic product (GDP) was 5.9 billion with a growth rate of $2.1 \%$. Total exports and imports were $\$ 4.5$ billion and $\$ 4.4$ respectively. The major trading partners of Bahrain are Saudi Arabia, India, Japan, USA, UK, Jordan, Egypt, Iran, Syria and Lebanon.

Bahrain has established a financial center with both onshore and offshore operations and the financial sector accounted for $23 \%$ of GDP. In 2001 and in terms of economic freedom Bahrain was ranked number (9) in a list of worldwide countries. Bahrain has a stock exchange with (41) listed companies in 2002. The value of total market capitalization of these companies was $\$ 715235$ million and the total number of shareholders was 103884 .

The Commercial Companies Act of 1975 has some regulations, rules and procedures regarding different types of companies and partnerships registered in Bahrain. Three types of companies exist in Bahrain: joint stock companies, shareholding companies and companies with limited liability. Commercial companies Act requires all limited liability companies to prepare financial statements and to have them audited.

\section{THEORETICAL BACKGROUND}

\section{Quality: Definition And Aspects}

Quality has been defined as: "conformance to customer expectations in terms of features and performance of the product or service involved as promised by the organization". Customers are defined as the receivers of the output or the service of an organisation (see Atkinson et al., 2001 and Morse et al., 1987). There are three aspects that underlie the overall quality of a product or service.

- Grade. This relates to differences in degree, worth, or ranking between products or services that have the same functional use (Garrison and Noreen, 1994).

- Quality of design. The degree to which a company's design specifications for a product or service meet customers' expectations for the grade level chosen (a particular grade calls for certain design feature). That is, a product or service has a high quality of design if, for the grade level chosen, it has all the features and operates in the way that customers would expect it to operate (Morse et al. 1987).

- Quality of conformance. The degree to which the actual product that is manufactured or the actual service that is rendered meets its design specifications and is free of defects or problems that might affect appearance or performance (Morse et al. 1987, p.11).

\section{Quality As A Management Tool}

The concept of total quality management was first introduced by Figenbaum (1951) who noted that the cost of poor quality could occur both from errors in the design of the product as well as in the production of the product. During 1960's Juran recognized the need for management to be involved in the achievement of quality. He recommended that finance and control groups measure the cost of waste due to poor quality and report it to 
management and that management involve themselves directly in those efforts. Ishikawa (1985) published a guide to total quality control that expanded the array of techniques available for workers to improve product quality.

The understanding of quality costs as a management tool is critical and can provide valuable benefits to a firm's quality program, including improved quality, higher productivity and better cost management (Juran, 1985; Morse and Roth, 1987). In trying to control the costs of quality, an organization must first be able to calculate its total cost of quality. Quality costs should be measured to the extent possible and practical and the benefits of those costs estimated. Such calculations are likely to use estimates rather than actual figures (Rainbor et al., 1996).

The quality movement can be divided into two opposite approaches and a middle of the road approach that attempts to reconcile the other two. The first is the cost of quality approach pioneered by Juran (1985) who urged manufacturers to "design in" quality at the beginning of the process, not to "inspect-in" quality at the end of the production line. Stanleigh (1993) states that one of the building blocks of quality management is that before a problem can be solved, it must first be measured. He recommends that by converting this measure into dollars it allows management to promote quality as a business parameter.

The second approach is that of Deming (1990) who sees the measurement of cost of quality as a waste of time and that the focus should be on achieving zero defects. Crosby (1980) takes a middle of the road approach that recognizes the importance of focusing on eliminating defects and sees the measurement of quality costs as useful but should not be the focus. He argues that a measurement of quality costs should not be for management control, but for the development of quality thinking within the organization. The understanding of quality costs and the use of such information as a management tool is critical and can provide valuable benefits to a firm's quality program, including improved quality, higher productivity and better cost management (Juran 1985 and Morse and Roth 1987).

\section{Quality Costs And Reports}

Historically, quality costs have not been given separate recognition in the accounting system. In most instances the cost of quality is "buried " in a variety of general ledger accounts, including work-in-process inventory and finished goods inventory (for rework, scrap, preventive maintenance, marketing and advertising costs (e.g. recall products) and personnel costs (e.g. training).

Cost of quality is a measurement tool which provides a measure of cost specifically associated with the achievement or non-achievement of product or service quality - as defined by all product or service requirements established by the company and its contracts with customers and society (Hagan 1985, p.3). The cost of quality can be substantial; on average it is 20 to 25 percent of sales for many US firms (see Ostenega and Youde (1992). The measurement of quality performance is of great importance in the business sector, particularly in view of the considerable efforts being put into the implementation of quality management techniques across a wide range of organizations.

In trying to control the cost of quality, an organization must first be able to calculate its total cost of quality. Juran and Gryna (1993) advocate the measurement of quality costs on a periodic basis as a management control tool. Quality costs should be measured to the extent possible and practical and the benefits of those costs estimated. Such calculations are likely to use estimates rather than actual figures (Raiborn et. al., 1996).

To collect quality costs, there needs to be a classification of such costs to determine the expenditure type. The bulk of all quality costs incurred by a company are associated with the quality of conformance. These costs are broken down into four broad groups. Two of these costs - known as prevention costs and appraisal costs - are incurred in an effort to keep poor quality of conformance from occurring. The other two groups of costs - known as internal failure costs and external failure costs - are incurred because poor quality of conformance has occurred.

The costs of quality are accumulated and reported in a cost of quality report. The information provided by a cost of quality report is used by managers in several ways (see: dale and Plunkett, 1990; John et al., 1991; Garrison and Noreen, 1994 and Ross, 1995). 
- Quality cost information helps managers see the financial significance of quality. Because quality costs are not normally accumulated by the accounting system, managers are generally not aware of the size and significance of these costs. Thus, cost of quality focuses attention on how costly poor quality can be.

- To evaluate whether the distribution of quality costs is efficient or not. The report shows how much a firm spends in prevention and appraisal activities (voluntary expenditure) and the cost of internal and external failure (involuntary costs). Quality costs should be distributed more towards prevention and appraisal activities and less towards failure of various types. Otherwise, this may indicate a poor distribution of quality costs. However, while there are high payoffs from initially shifting quality costs from the appraisal, internal failure, and external failure categories to the prevention category, there is no "optimal" distribution of quality costs among the four categories.

- To help management in their efforts to reduce quality costs. The information accumulated in the quality cost report provides a basis for establishing budgets for various elements of quality costs. These budgets can then be used as a basis for evaluating management performance and success with respect to reducing total quality costs. Properly designed quality cost reports assist in determining the type of activities that are most heretical in reducing quality costs and when quality costs are accumulated in sufficient detail, quality cost reports help management priorities quality improvement activities and promotes the idea that quality is everyone's responsibility.

- $\quad$ To identify the relative importance of quality problems faced by the firm. For example, the quality cost report may show that scrap is a major quality problem or that the company is incurring high warranty costs. With this information, management can see where to focus its efforts.

Although a quality cost report is useful, it is important to note that measuring and reporting quality costs do not solve the identified quality problems. Moreover, some important, but difficult to measure and quantify, quality costs are typically omitted from the quality cost report, such as unrecorded opportunity costs, e.g., loss of further income arising from poor product design or customer ill will.

Beside the financial measures of quality costs (prevention, appraisal, and failure costs), companies use nonfinancial measures (e.g., number of customer returns, repeat purchases, the number of customers' complaints, delivery delays, number of defects and staff turnover) in order to evaluate how well their actual performance satisfies customer needs. Managers also pay close attention to first-time pass rate in each process and in the company as a whole, which indicates whether products are being built to specifications. Non-financial measures are helpful in revealing the future needs and preferences of customers. They also indicate the specific areas which need improvement (Horngren et al., 2000) and may provide a viable alternative to quality costs as an overall measure of quality. Shank and Govindarajan (1994) indicate that non-financial measures are essential to provide feedback to managers in their pursuit of quality. Finally, in order to establish an overall measure of quality, it is necessary to establish a range of measures (financial and non-financial) which give an overall picture of the quality of the products or services of the organization (Bowie, 1993).

\section{Description Of The Study}

The population of the study consisted of all types of firms operating in Bahrain. According to the Directory of the Ministry of Commerce for the year 2002, there were (315) companies. A sample of (100) companies was selected at random from the population. A questionnaire was developed to collect the data needed for the study. While recognizing the accepted limitations of this type of research instrument, it was considered appropriate given the exploratory nature of the study and the ability to survey a wider number of firms. The questionnaire consists of four sections. Section one contains information about the nature of business operations, size of the firm as measured by the number of employees and annual sales revenue. Section two provides information about quality certification, the date when companies were quality certified, the factors influencing companies' decision to obtain ISO certification, and the effect of quality certification on quality costs. Section three collects information on the classification of quality costs, measuring and reporting costs of quality, the uses of quality costs reports, and the reasons why some companies do not report quality costs. The last section elicits information about quality performance and customer satisfaction measures. Since it is impossible to predict how questionnaire items will be interpreted by respondents, the 
questionnaire was pilot tested on two firms. The results and feedback of the pilot test were used to refine the questionnaire and a final draft was developed.

The questionnaire was mailed to the entire sample of (100) companies. Access to the firms was obtained through the author with the help of a group of accounting students who were taking the "Current Issues in Accounting" course (Acc.491) during the second semester 2001/2002. The course outline includes a unit on "cost of quality". We visited each firm in the sample and asked the manager of the accounting department, quality assurance manager or someone who is familiar with cost of quality to fill in the questionnaire. Eighty one companies responded, an overall response rate of $(81 \%)$ which was considered appropriate for the study.

It should also be pointed out that the study is descriptive. Therefore, no testable hypotheses or additional analysis comparing and examining differences among subgroups of respondents will be undertaken. Finally, the statistical package for social sciences (SPSS) was used to analyse the data.

\section{RESULTS AND DISCUSSION}

\section{A. Respondents' Characteristics}

To get some background information about the responding companies, respondents were asked to indicate whether or not they are ISO certified, the type of their firms (service, merchandising or manufacturing), the total number of employees, and the sales revenue. These last two characteristics were used as proxies of size. Table (1) shows the results.

Table 1

Respondents' Characteristics

$(\mathrm{N}=81)$

\begin{tabular}{|c|c|}
\hline a. Type Of Firm & $\%$ \\
\hline Manufacturing & 40.7 \\
\hline Merchandising & 8.6 \\
\hline Service & 50.7 \\
\hline Total & 100.0 \\
\hline \multicolumn{2}{|l|}{ b. Number Of Employees } \\
\hline Less than 100 & 34.6 \\
\hline 100 to 200 & 14.8 \\
\hline 201 to 300 & 8.6 \\
\hline 301 to 500 & 17.3 \\
\hline More than 500 & 24.7 \\
\hline Total & 100.0 \\
\hline \multicolumn{2}{|l|}{ c. Annual Turnover } \\
\hline Less than BD1 Million & 27.6 \\
\hline BD1 to less than BD2 Million & 19.7 \\
\hline BD2 to BD5 Million & 17.1 \\
\hline More than BD5 Million & 35.6 \\
\hline Total & 100.0 \\
\hline \multicolumn{2}{|l|}{ d. ISO Certification } \\
\hline Yes & 58.0 \\
\hline No & 42.0 \\
\hline Total & 100.0 \\
\hline
\end{tabular}

The table shows that all types of firms are represented in the sample. However, the majority are service and manufacturing firms. Only 7 companies are in the merchandising sector. Both the number of employees and the sales revenue indicate that firms are of different sizes. Five companies did not report their annual turnover, probably 
because they are organized as a single proprietorship or closely-held companies. Usually, these types of firms do not disclose their financial information and they keep them confidential.

The majority of respondents (47) companies (58\%), are ISO certified and 34 are not. Of this number two companies are in the process of obtaining ISO certification. One of the respondents who did not obtain ISO certification stated that they have a good system of keeping records as well as total quality management. This indicates that companies recognize the need to incorporate quality management into their business operations as a competitive weapon in their environment. The majority of the firms which are not ISO certified (27) are service firms such as, banks, investment and insurance companies and auditing firms. Five merchandising firms and two small scale manufacturing firms did not obtain ISO certification. These results indicate that more emphasis is given to manufacturing firms emphasize ISO certification. The reason is that cost of quality is particularly applicable in manufacturing firms, and may be difficult to implement in the service sector. It is generally perceived that quality costing is not an easy task to carry out in small organisations and in the service sector (Bowie, 1993).

Thirty firms (63.8\%) of the 47 firms obtained quality certification more than three years ago (some since 1995). All of the ISO certified companies stated that they have partial certification (e.g. ISO 9001 about the requirements to enhance customer satisfaction; 9002 and 14001 - Environmental Management System). They want to experience ISO system and get an idea about the effects of ISO on the business before they seek quality certification in other areas.

Most of the questionnaires were completed by the finance manager and other persons occupying positions require good knowledge of the issue of quality costs. A number were completed by project and business development manager, training and development manager and quality assurance manager. Table 2 presents the job titles of questionnaire respondents.

Table 2

Job Title Of Respondents

\begin{tabular}{|c|c|c|}
\hline Job Title & $\mathbf{F}$ & $\%$ \\
\hline Finance manager/Controller/Accountant & 72 & 88.9 \\
\hline Manager of quality assurance & 1 & 1.2 \\
\hline Quality manager/ quality coordinator. & 2 & 2.5 \\
\hline Project development manager & 2 & 2.5 \\
\hline General manager/ Managing director. & 2 & 2.5 \\
\hline Training manager. & 1 & 1.2 \\
\hline Manager, treasury operations. & 1 & 1.2 \\
\hline Totals & 81 & 100.0 \\
\hline
\end{tabular}

\section{B. Motivation For Quality Certification}

This section highlights the factors which motivated Bahraini companies to obtain quality certification. The adoption of total quality management by Japanese companies was motivated by the desire to compete in Western markets. The US companies followed suite because they started to lose their domestic marketto Japanese companies. In Bahrain, the (47) firms which are ISO certified were asked to indicate the importance of a number of factors in influencing their decision to obtain quality certification (see Table 3). The most important factors were: market competition, quality improvement and cost reduction. Market competition received the highest percentage. About (93\%) of the respondents stated that it is moderate to extremely important. More than $70 \%$ of respondents have been driven by the need to reduce their costs and about $83 \%$ indicated that pressure from customers played a moderate to extremely important role. The reason is that the certification itself carries a high value for the customers, probably because they are aware of the purpose and the consequences of obtaining ISO certification. This awareness of ISO certification by customers supports and helps confirm the first motive for ISO certification "market competition". 
Almost all respondents acknowledged that quality improvement is an extremely important factor. The overseas requirement was of moderate importance. To promote quality and satisfy customers, government involvement through legislation is required. However, there was no common opinion about the influence of government contracts among the respondents. The reason is that the government does not impose strict provisions on the companies with regard to obtaining quality certification. In Bahrain, Act No. 36 for the year 2002 requires that government contracts and purchases should be through tenders. The tender could be local and in this case it is limited only for local contractors or suppliers who are registered in the Kingdom of Bahrain and are allowed to carry out commercial activity. The tender could also be international where both registered and unregistered (i.e., international) vendors and contractors are allowed to participate in it. However, international companies are required to register according to the local rules in Bahrain within 30 days of the date in which they are selected to carry out business with the government. The Tenders Council decides to choose between local and international contractors based on certain criteria such as, the size and level of complexity of the constructions required and the nature of the goods and services.

The Act does not specifically require companies that do business with the government to have ISO certification. However, the contractors and vendors are required to produce evidence that they are qualified to do the business. They should be qualified financially, technically and professionally and have the necessary equipment, expertise, administrative ability, experience and good reputation to carry out the purchase contract and the contractors are required to prove that by producing the required documents. Moreover, the government liberalized the economy and opens its procurement to foreign investors. Foreign direct investment stood at $\$ 2.7$ billion in 2002 . To encourage foreign investment the country gives many incentives for foreign investors. For example, foreign investors are allowed to invest and trade in shares in Bahrain Stock Exchange. These requirements implicitly indicate that contractors who do business with the government should be highly qualified.

Other factors added by respondents were: corporate image; customer loyalty and to protect and improve the environment (ISO 14001). In summary, the motivation factors behind quality certification are competition in the market, continuous quality improvement; oversees requirements and cost reduction. These results are inconsistent with those found in some other countries. For example, Hudson (1995) found that Australian manufacturing firms obtain quality certification for the following reasons: continuous improvement; to gain a competitive edge; overseas requirement; and customers' pressure (private and government sectors). In addition, there are some differences between Bahraini companies and companies in other countries.

Table 3

Motives For Quality Certification

$(\mathrm{N}=47)$

Frequency and percentage distribution of responses

\begin{tabular}{|c|c|c|c|c|c|c|c|c|c|c|c|}
\hline \multirow[t]{2}{*}{ Motive } & \multicolumn{2}{|c|}{$\begin{array}{c}\text { Not } \\
\text { Important } \\
1\end{array}$} & \multicolumn{2}{|c|}{2} & \multicolumn{2}{|c|}{$\begin{array}{c}\text { Moderate } \\
\mathbf{3}\end{array}$} & \multicolumn{2}{|c|}{4} & \multicolumn{2}{|c|}{$\begin{array}{c}\text { Extremely } \\
\text { Important } \\
5\end{array}$} & \multirow[t]{2}{*}{ Total } \\
\hline & $\mathrm{N}$ & $\%$ & $\mathrm{~N}$ & $\%$ & $\mathrm{~N}$ & $\%$ & $\mathrm{~N}$ & $\%$ & $\mathrm{~N}$ & $\%$ & \\
\hline 1. Customers' pressure & 5 & 10.6 & 3 & 6.4 & 7 & 14.9 & 11 & 23.4 & 21 & 44.7 & 46 \\
\hline 2. Government contracts & 5 & 10.9 & 5 & 10.9 & 8 & 17.4 & 15 & 32.6 & 13 & 28.3 & 47 \\
\hline 3. Market competition & 4 & 8.5 & 2 & 4.3 & 6 & 12.8 & 11 & 23.4 & 24 & 51.1 & 46 \\
\hline 4. Overseas requirements & 6 & 13.0 & 3 & 6.5 & 9 & 19.6 & 11 & 23.9 & 17 & 37.0 & 46 \\
\hline 5. Quality improvement & 1 & 2.1 & 4 & 8.3 & 1 & 2.1 & 8 & 16.7 & 34 & 70.8 & 47 \\
\hline 6. Cost reduction & 2 & 4.9 & 2 & 4.9 & 9 & 22.0 & 8 & 19.5 & 20 & 48.8 & 41 \\
\hline
\end{tabular}

The relationships between ISO certification and both type of business and company size are examined. It was significant at the .05 level in the case of company size measured by sales revenue $(\mathrm{P}=.045)$. This indicates that ISO certification is associated with company size and large size companies have a higher tendency to obtain ISO certification than small size companies. There was also an association between ISO certification and the type of firm (manufacturing, merchandising or service). Again, the relationship was significant at the .01 level $(\mathrm{P}=.008)$. This confirms respondents' comments that quality certification is most likely in manufacturing firms rather than 
merchandising firms which sell goods to customers without making changes in the basic form of the goods purchased. Service firms should provide high quality service to the customers but the need for ISO certification in such firms may be less than in manufacturing.

Finally, to help the readers understand the study better, the effects of size, type of firm and ISO certification were examined in relation to the six motives for ISO certification mentioned above (Table 3). The relationship between ISO certification and motive 1 "customers' pressure" only was significant $(\mathrm{P}=.037)$. In the case of company size and motives the relationship was significant in motives 1 and 3 "market competition" ( $\mathrm{P}=.028$ and .068 respectively). There was no significant relationship between company type and any of the motives for ISO certification.

\section{Effects Of Quality Certification}

To evaluate the effects of quality certification experienced in their operations outcomes, Table 4 shows that ( $85 \%)$ of the certified firms (40 companies) indicated that the number of customers' complaints decreased, while $8.5 \%$ (3 companies) indicated that there was no effect on the number of complaints. The costs of rework also decreased in about $79 \%$ of the responding firms. About 57\% indicated that the amount of warranty expense decreased, and $31 \%$ indicated that there was no effect. It is surprising that $12 \%$ reported that warranty expense increased. One explanation for this result is that a time lag exists between quality improvement effort and accomplishment.

About (58\%) indicated that there was a reduction in the total cost of quality. In $11 \%$ of the firms it had no effect on quality costs and in $31 \%$ the cost of quality increased. This could be explained on the grounds that the cost of quality is expected to increase in the short run because of additional expenditure on prevention costs. According to quality standards literature, cost of gaining and maintaining certification requires a large human resources input. However, the increase in total quality cost in the short run does not mean it will be a long term trend. Sales volume increased as indicated by $67 \%$ of the certified companies. However, there was no effect on sales volume in other firms and in some firms there was a decrease. This may be because the main purpose of quality certification is to satisfy customers and reduce their complaints. Although there are factors other than quality which influence sales volume, respondents were asked to limit their answers to the effect of quality only.

Table 4

Effects Of Quality Certification $(\mathrm{N}=47)$

\begin{tabular}{|l|rr|rr|rr|r|}
\hline \multicolumn{1}{|c|}{ Effect } & \multicolumn{2}{|c|}{ Increase } & \multicolumn{2}{c|}{ Decrease } & \multicolumn{2}{c|}{ No Effect } & \multicolumn{2}{c|}{ Total } \\
\hline & $\mathrm{F}$ & $\%$ & $\mathrm{~F}$ & $\%$ & $\mathrm{~F}$ & $\%$ & \\
\hline a. Number of customers complaints & 3 & 6.4 & 40 & 85.1 & 3 & 8.5 & 47 \\
\hline b. Cost of rework & 2 & 4.7 & 34 & 79.1 & 7 & 16.3 & 43 \\
\hline c. Amount of warranty expense & 5 & 11.9 & 24 & 57.1 & 13 & 31.0 & 42 \\
\hline d. Total cost of quality & 14 & 31.1 & 26 & 57.8 & 5 & 11.1 & 45 \\
\hline e. Sales volume & 31 & 67.4 & 2 & 4.3 & 13 & 28.3 & 40 \\
\hline
\end{tabular}

It should be pointed out that a British government survey revealed that $89 \%$ of ISO 9000 registered companies reported greater operational efficiency, $48 \%$ reported increased profitability, $76 \%$ reported improvements in marketing and 26\% reported increased export sales. Other British study for British Standards Institution, estimate that registered firms reduce operating cost by $10 \%$ on average. Also a number of U.S. firms have reported benefits ranging from increase in sales to communications improvements. Finally, Du Pont attributes the following results to the adoption of ISO certification in their plants: 
- $\quad$ On time delivery (i.e., the percentage of shipments made on or before the scheduled delivery date) at one plant increased from $70 \%$ to $90 \%$.

- $\quad$ Cycle time (the time required to complete a product or service) at one plant decreased from 15 days to 11.2 days.

- $\quad$ First-pass yield (the ratio of good output to total output) at one plant increased from $72 \%$ to $92 \%$

- $\quad$ Test procedures were reduced from 3000 to 1100.

\section{Reporting Costs Of Quality}

As part of their quality control system, many well managed companies accumulate these costs on a quality costs report. In order to evaluate Bahraini companies' behavior toward cost of quality to both types of respondents (firms which are ISO certified and those which are not) were asked to describe their involvement in measuring and reporting that cost. The results show that of the (81) companies responding to this question, 40 companies (51.3\%) currently measure the cost of quality and prepare a cost of quality report. 22 companies (28.2\%) indicated that they plan to implement it in the future; 16 companies $(20.5 \%)$ had no plans of implementing cost of quality reporting. It is to be pointed out that the (40) companies which measure and report cost of quality are ISO certified. One respondent in the group who had no plans to implement cost of quality reporting in the future indicated that:

"their system is not old enough to report data about cost of quality. Our aim is to adapt to the new culture that ISO has introduced. Once quality becomes part of our daily routine and a way of our life, we can emphasise more on quality performance measures".

Another respondent added that "we are ISO certified but we have not yet measured and reported quality costs. Maybe after one year from now the picture will be clearer". This indicates that some companies in Bahrain are more interested to obtain quality certification without giving much importance for cost of quality reporting. Also some service companies mentioned that they deal with service operations. So, they did not place much emphasis on cost of quality reporting.

The results are, to a large extent, consistent with previous research. For example, the adoption rate in Qu and Oliver study (1997) is 39\%; Ross (1993) 47.5\%; Plunkett and Dale (1984) 50\%; Duncalf and Dale (1985) 32\%. Moreover, Ross et al. (1996) found that only $12 \%$ of hospitals surveyed indicated that they measured COQ. A number of factors appear to have influenced the low rates of adoption of cost of quality reporting across various types of organizations (see Wheldon and Ross, 1998).

First, quality reporting (including cost of quality) was seen to be in the realm of quality managers in organizations. Quality managers have focused extensively on non-financial measures of quality (e.g. reducing rates of scrap) and their lack of accounting knowledge is likely to have restricted their ability to produce cost of quality reports, which encompass all four categories of costs.

Second, the concept of cost of quality reporting has only been introduced into the accounting discipline in relatively recent times. It was first included in a leading management accounting text (Horngren and Foster, 1987). It has taken some time for this concept to filter through into accounting practice. In this regard one respondent commented that "you should explain what a cost of quality report looks like and what it contains".

A third explanation is "accounting lag", where administrative innovations such as changes to accounting systems will always tend to lag behind technical innovations such as quality management. This explanation, however, loses credence over time.

Fourth, the existing COQ model may be only appropriate for manufacturing firms. The four cost categories, even adjusted for differences in terminology between industries, may need a classification system for nonmanufacturing organizations. In this regard, one respondent indicated that they "deal with service operations. So, they did not place much emphasis on quality cost and reporting". 
When the firms which adopted COQ reporting are grouped with those companies which intend to implement it in the future, the result of the grouping indicates that (46) companies (56.8\%) will incorporate COQ reporting into their operations to support their quality initiatives which may indicate that respondents are aware of the importance of measuring and reporting quality costs.

Finally, partial correlation was conducted between ISO certification both type of firm and size measured by sales revenue and number of employees. There was no significant relationship (at the .10 level of significance) between ISO certification and type of firm and size.

\section{E. Classification Of Quality Costs}

Not all companies (the forty companies which indicated that they measure and report quality costs) classified costs using all four cost categories; prevention, appraisal, internal failure and external failure costs, in their reporting system. Analysis of data shows that 35 (87.5\%) respondents used all four cost categories. The remaining 5 companies use two-part classification, prevention and failure costs. One explanation for this result is that if the objective of the COQ system is to reduce failure costs, (the previous findings suggest that respondents were interested in reducing customer complaints and rework/scrap) then there is little point in distinguishing between prevention and appraisal categories (see Plunkett and Dale, 1984).

Respondents were also asked how they collected cost data for each quality cost category. In the case of prevention costs the majority (77.5\%) relied on estimates. This may be because prevention costs are difficult to measure accurately (see Ross, 1993 and Gupta and Campbell, 1995). If the firm's main objective for the COQ system is to identify high cost problem areas then the precision of costs may not be important (Dale and Oakland, 1994; and Qu and Oliver, 1997). However, with regards to appraisal and failure costs, all respondents used estimates and actual costs. This may be because the information about these two cost categories are readily available from the accounting system. For control purposes both estimated and actual costs are used. However, firms which use two-part classification of quality costs used actual costs for both prevention and failure costs.

In the majority of companies the cost of quality report was produced by the quality manager and accounting manager. Other answers added by respondents were: management accounting; engineering; quality engineer; marketing manager; financial controller; and different departments or directorates. The report covers the whole company in 26 firms and in the remaining 14 firms it covers specific areas in the business. Of the firms responding to this question one company which indicated that the report is for the whole company added "except finance which is taken care of by internal/external auditors".

About (63\%) of the firms ( 25 companies) used the help of outside consultants to assist in the preparation of the cost of quality report. One company added that "initially we depended on outside consultants but now we are on our own". This result is consistent with Qu and Oliver (1997) study. However, it is inconsistent with the literature which indicates that the preparation of the report should be the responsibility of both personnel and accounting departments (see Gupta and Campbell, 1995 and Morse and Poston, 1993).

Juran (1995) indicates that quality cost reports ought to be prepared on a periodic basis as the central management control tool. Most of the firms produce the report annually; semiannually or quarterly. The three companies whose reports cover specific areas, produce the report on a daily basis. It is to be noted that none of the respondents prepare the report semiannually or weekly. The COQ report is addressed to the General Manager in most of the companies, while it is sent to the quality manager in three companies. Some respondents added that copies of the report are sent to the Board of Directors; Executive Committee; Executive management; owners of firm; financial controller; plant manager and all departments' heads.

\section{F. Uses And Benefits Of Cost Of Quality Report}

When the respondents were asked about the uses of a cost of quality report, they indicated that they use it for product cost information and process improvement. Other uses of the report by these companies were, product 
improvement and suppliers' performance improvement (see Table 5). This shows that COQ is an integral part of continuous quality improvement. Cost reduction is a result of reduction in scrap costs and cost of rework of defective units and is achieved through better cost management. The use of quality cost data in quality cost planning is the least important factor. This shows that although the literature indicates that quality costs are being used for planning and control, they are not used in practice (see Qu and Oliver, 1997 and Plunkett and Dale, 1984). The results are consistent with previous research (see John et al., 1991). Other uses added by respondents were:

- $\quad$ Targeting areas of quality improvement, monitoring improvement efforts, motivating employees towards quality goals to ensure that total quality control is applied to all organization endeavors.

- $\quad$ Customer satisfaction and continuous improvement.

- $\quad$ These reports give a very good impact to the shop floor people. The effect of the cost of scrap is very much understood by all people.

Table 5

Uses Of Quality Cost Data

$(\mathrm{N}=40)$

\begin{tabular}{|c|c|c|c|}
\hline & & $\mathbf{F}$ & $\%$ \\
\hline a. & Product cost information & 29 & 72.5 \\
\hline b. & Process improvement & 40 & 100.0 \\
\hline c. & Product improvement & 37 & 92.5 \\
\hline & Quality cost planning & 40 & 100.0 \\
\hline & Suppliers performance improvement & 19 & 47.5 \\
\hline
\end{tabular}

\section{G. Companies Not Measuring Cost Of Quality}

As was mentioned previously, twenty two firms (36.7\%) do not measure and report cost of quality and 14 plan to adopt COQ reporting in the future (a total of 36 of 81). Many of these firms are ISO certified. How do they manage their quality to ensure that they are ISO compliant? Table 6 shows the reasons why some companies do not adopt COQ measurement and reporting. The most important reasons are: "the cost of producing the report (i.e., the large amount of resources required to support the system and the problems of maintaining a parallel register for collecting quality costs from the existing cost information system), "commitment of maintaining accurate system", "quality is part of the firm's culture", "competition not intense", and "extensive use of non-financial measures". The least important reasons are: "lack of support by management", "pressure extended on employees and managers from adopting the new system", "firms being unaware of the concept of quality costs", and "manufacturing complexity". Other reasons added by respondents were: lack of service providers; additional workload to prepare; lack of quality skills; and developing a parallel system with normal financial accounting creates some confusion. The factor that several respondents do not measure and report cost of quality because of cost is specific to Bahraini companies. With the exception of this factor, the results are consistent with the findings of previous research (see Gupta and Campbell, 1995; Ross, 1993 and Carr and Pnemon 1994).

Other comments added by respondents are: "cost of quality is an integral part of production costs", "it is very difficult to identify cost of quality". It is apparent that the most important reason relates to the additional costs of producing the report. One respondent added that "we do implement quality control but we do not specifically report on it". In this regard, one service firm (an insurance company) indicated that the service they provide (besides the document) is a promise to pay claims. At the underwriting stage, rates and quickness of response and clarity of insurance policy documents are important. The speed with which claims are attended to alongside the quantum agreed upon, are the important quality parameters for claims. While all these are extremely important factors in customer satisfaction, they are not easily quantifiable. 
Table 6

Reasons For Not Measuring And Reporting COQ

$(\mathrm{N}=36)$

\begin{tabular}{|c|c|c|c|c|c|c|c|c|c|c|}
\hline \multirow{3}{*}{ Reason } & \multicolumn{10}{|c|}{ Frequency and percentage distribution of responses } \\
\hline & \multicolumn{2}{|c|}{$\begin{array}{c}\text { Not } \\
\text { Important } \\
1 \\
\end{array}$} & \multicolumn{2}{|c|}{2} & \multicolumn{2}{|c|}{$\begin{array}{c}\text { Moderate } \\
\mathbf{3} \\
\end{array}$} & \multicolumn{2}{|r|}{4} & \multicolumn{2}{|c|}{$\begin{array}{c}\text { Extremely } \\
\text { Important } \\
5\end{array}$} \\
\hline & $\mathrm{N}$ & $\%$ & $\mathrm{~N}$ & $\%$ & $\mathrm{~N}$ & $\%$ & & $\%$ & $\mathrm{~N}$ & $\%$ \\
\hline a. Cost of producing the report & 2 & 5.6 & 2 & 5.6 & 15 & 41.6 & & 5.6 & 15 & 41.6 \\
\hline b. Commitment to maintaining accurate system & 4 & 11.2 & 2 & 5.5 & 11 & 30.5 & & 11.2 & 15 & 41.6 \\
\hline c. Lack of support by management & 16 & 44.4 & 1 & 2.8 & 5 & 13.9 & 8 & 22.2 & 6 & 16.7 \\
\hline d. Pressure on employees and managers & 12 & 33.4 & 13 & 36.1 & 2 & 5.5 & 8 & 22.2 & 1 & 2.8 \\
\hline e. Quality is part of the firm's culture & 0 & 0 & 2 & 5.5 & 7 & 19.4 & 4 & 11.2 & 23 & 63.9 \\
\hline f. Competition not intense & 4 & 11.2 & 2 & 5.5 & 8 & 22.2 & 9 & 25.0 & 13 & 36.1 \\
\hline g. Unawareness of the concept & 12 & 33.3 & 7 & 19.4 & 6 & 16.7 & 4 & 11.2 & 7 & 19.4 \\
\hline $\begin{array}{l}\text { h. Extensive use of non-financial performance } \\
\text { indicators }\end{array}$ & 0 & 0 & 4 & 11.1 & 11 & 30.6 & 8 & 22.2 & 13 & 36.1 \\
\hline i. Cost of quality focus on short term changes in cost & 11 & 30.6 & 6 & 16.7 & 10 & 27.8 & 8 & 22.2 & 1 & 2.7 \\
\hline j. Manufacturing complexity & 12 & 33.3 & 6 & 16.7 & 9 & 25.0 & 6 & 16.7 & 3 & 8.3 \\
\hline
\end{tabular}

Finally, the following reasons, regarding why some firms choose not to measure and report quality costs, have been cited in the literature (Ross, 1993; Carr and Ponemon, 1994; Gupta and Campbell, 1995 and Qu and Oliver, 1997).

- $\quad$ Firms are unaware of the concept.

- $\quad$ Lack of support from management.

- $\quad$ The time lag between expenditure for conformance and the change in failure costs.

- $\quad$ Large amount of resources required to support the system.

\section{H. Quality Performance And Customer Satisfaction Measures}

As customer satisfaction is one of the major objectives of any business enterprise, this objective is to be emphasized by high quality performance. To monitor quality performance managers look at measures such as warranty claims, customer complaints and defects. All questionnaire respondents (i.e. both types) were asked about the financial and non-financial indicators used to measure quality performance and customer satisfaction. Table 7 shows the financial measures used to evaluate quality performance. Not all firms answered these questions and the majority of respondents used them.

Table 7

Financial Measures Of Quality Performance $(\mathrm{N}=81)$

\begin{tabular}{|c|c|c|c|}
\hline Financial Measures & Yes & No & Total* \\
\hline a. Warranty repair expense & 44 & 29 & 73 \\
\hline b. Liability claims & 53 & 18 & 71 \\
\hline c. Lower prices of products sold & 50 & 23 & 73 \\
\hline d. Foregone contribution margin on lost sales & 43 & 26 & 69 \\
\hline
\end{tabular}

* Total is not 81 because some firms did not answer this question.

Respondents were also asked about the use of non-financial measures. The most important non-financial indicator is the number of customers' complaints (see Table 8). It is used by almost all companies (100\%). Other three important non-financial indicators are customers' feedback, quality audit report and non-conformance report. Other non-financial indicators which were also considered important by respondents are: on-time delivery; number of defective units shipped and excessive customer response time. Customer response time is the amount of time from 
when a customer places an order for a product or requests a service to when the product or service is delivered to the customer. Finally, one respondent (insurance company) added that:

"our industry is a small scale unit which is concentrating its efforts to establish their products in the market. We are aware of non-financial indicators only to measure quality performance. Except for minor problems such as delays in delivery or shade variation our quality performance is good. We faced no legal action or had to pay compensation for failure".

It is apparent that non-financial indicators are used extensively. The majority of companies rely on such measures to improve their quality performance regarding customer satisfaction. Rayner and Porter (1991) examined the use of non-financial indicators for quality measurement. The results of their study identified two major benefits: the costs could be collected and reported on a daily basis and corrective action can be taken almost immediately.

Table 8

Non-Financial Measures Of Quality

\begin{tabular}{|l|c|c|c|}
\hline Non-Financial Indicators & Yes & No & Total \\
\hline a. The number of defective units shipped to customers & 41 & 31 & 72 \\
\hline b. The number of customers' complaints & 68 & 7 & 75 \\
\hline c. Excessive customer response time & 52 & 20 & 72 \\
\hline d. On time delivery & 65 & 10 & 75 \\
\hline e. Customer feedback & 70 & 7 & 77 \\
\hline f. Quality audit report & 55 & 21 & 76 \\
\hline g. Non-conformance reports & 42 & 29 & 71 \\
\hline
\end{tabular}

* Total is not 81 because some firms did not answer this question.

\section{SUMMARY AND CONCLUSION}

The purpose of this study was to provide empirical evidence on quality certification and cost of quality measurement and reporting by Bahraini companies. The results show that a high percentage of the responding firms obtained quality certification. During 1990's, the matter of quality certification became familiar in a way that Bahraini companies have taken initiatives of getting ISO 9000 certification. In 1993, only two companies received ISO certification. By the end of the millennium, the number exceeded (50) companies, and it is expected to increasing. It is worth stating that according to the records of the Ministry of Commerce-Directorate of Standards and Metrology the total number of ISO certified companies in Bahrain was 95 on March 6, 2004.

The rate of adoption of $\mathrm{COQ}$ reporting is low. However, the majority is aware of the fact and is planning to adopt COQ reporting in the future. If we include those companies which intend to adopt COQ reporting in the future, the results indicate a reasonable rate of adoption. For many of the companies which have no intention of adopting a COQ reporting system, non-financial indicators were used as performance measurement tools and many of the firms stated that quality was part of the firm's culture.

At the end of the questionnaire respondents were asked to add any comments they feel relevant to the study. The following comments were added:

- Quality is the key success for any company especially in the coming future. With all challenges quality systems should be assisted internally and externally and feedback must be gathered to improve the system.

- $\quad$ One firm suggested that they want a scheme administrator and quality lead manager.

- Calculation of cost of quality in construction industry is not very common in this part of the world. Certification is considered as a marketing tool rather than improvement tool. He hopes that the University of Bahrain will create awareness of this aspect amongst its students.

- We highly focus on all aspects of total quality management. The manufacturing process takes care of customer needs and tries to exceed expectations for achieving customer satisfaction. 
The quality programs are quite new concepts in Bahrain. However, Bahraini companies realize the importance of those programs in improving their production processes and performance, satisfying the customers and ultimately sustaining the competitive advantage. There is no doubt that measuring and reporting cost of quality would provide firms with important information to measure quality improvement and control costs associated with quality. The benefits of such reports are likely to cover its costs.

\section{LIMITATIONS AND AREAS FOR FURTHER RESEARCH}

One limitation of the study is that when respondents were asked whether or not they prepare quality costs report one respondent stated that we should explain what a cost of quality report look like and what it contains. This implies that the respondent is not much familiar with the concept of quality. He also added that most organizations give less importance to quality factors due to very low level of accountability and monopolies.

The most important limitation of the paper is that it does not attempt to assess the actual impact of ISO certification and cost of quality reporting on the Bahraini firms. Given that ISO certification results in the decrease in total costs of quality and the increase in sales volume, a simple analysis of sales, profitability and stock prices before and after ISO certification and measurement of costs of quality would corroborate those claims. Therefore, further research is needed to evaluate whether quality management had resulted in any gains in sales, cost reduction and as a result increased profitability. Although survey questionnaires are useful but they have some limitations and it is normal to supplement them with other data.

A case study approach with semi-structured interviews could also be conducted in those firms which claim to have adopted cost of quality reporting. Issues that could be raised are: Who is the initiator of the idea? How did they come to know about quality costs? What is the distribution of quality costs? (i.e., the relationship between quality cost components). What are the changes required in the accounting system? Do they review the chart of accounts and prepare quality cost manual? Do companies incorporate a topic on quality related costs in their training programs? Do they disclose quality costs information for employees? What is the primary target of adopting cost of quality reporting in the future?

\section{RECOMMENDATIONS}

In the light of the results, it is recommended that an on-going analysis of the cost of quality is critical. Shank (1989) was puzzled by the lack of cost of quality analysis in accounting curricula and accounting journals. In addition, a series of seminars, workshops, publications, consultancy services and conferences informing firms about best practices to build awareness, knowledge and competence, in measuring and reporting quality costs, should be conducted. Moreover, accountants in Bahrain should introduce cost of quality reports to the management of their organizations.

\section{REFERENCES}

1. ANSI/ASQC A3-(1978), Quality Systems Terminology, Milwaukee, WI:American Society for Quality Control.

2. Bowie, Neil (1993), The use of quality performance measures in diverse organizations, A paper presented at the $16^{\text {th }}$ Annual Congress of the Eurpoean Accounting Association, Turku-Finland, April 28-30.

3. Carr, L. P. and L. A. Ponemon (1994), The behavior of quality costs: Clarifying the confusion, Journal of Cost Management, Summer, pp.26-34.

4. $\quad$ Casey, R. W. (1990), The Changing World of the CEO, PPM World, 24, no.2, p.31.

5. Crosby, P.B. (1980) Quality is Free, The Art of Making Quality Certain, McGraw-Hill, New York, USA.

6. $\quad$ Crosby, P.B. (1983) Quality Without Tears, The Free Press, London.

7. Dale, B. G. and Plunkett, J.J. (1990), Managing Quality, Published Philip Allan, London.

8. Dale, B. G. and Oakland, J. (1994) Quality Improvement Through Standards, Stanley Thornes (publishers) Ltd., $2^{\text {nd }}$ Edition, pp.68-84. 
9. Dane, A.J., (1982) Quality Costs as a Management Tool, Quality Assurance, Vol. 8 No. 4, December, pp.9698.

10. Deming, W. (1986) Out of the crisis, Mass. Institute of Technology, Center for Advanced Engineering Studies.

11. Duncalf, A.J. and B.G. Dale (1985), How British Industry is Making Decisions on Product Quality, Long Range Planning, Vol.8, No.5, pp.81-85.

12. Edmonds, T.P., Tsay, B., and Lin W., (1989) Analyzing quality Costs, Management Accounting USA, November pp.25-59.

13. Figenbaum, A. V. (1954), Total Quality Control, Engineering and Management, Third edition, McGraw-Hill Book Co., New York.

14. Garrison, R. and E. Noreen (1994), Managerial Accounting, $7^{\text {th }}$ edition, Illinois, Irwin.

15. Garvin, D. (1985) The New York Times, 134 March, 3, p. F3.

16. Garvin, D. (1987) Competing on the Eight Dimensions of Quality, Harvard Business Review, NovemberDecember, pp.101-109.

17. Gupta, M., and Campbell, V.S. (1995), The Costs of Quality, Production and Inventory Management Journal, Third Quarter, pp. 43-49.

18. Hagan, John T. (1985), Quality Cost - the Economics of Quality Improvement ASQC Quality Press.

19. Horngren C.T, and G. Foster, (1987), Cost Accounting: A Managerial Emphasis, $6^{\text {th }}$ edition, Prentice Hall, New Jersey.

20. Horngren C.T, and G. Foster, and Datar (2000), Cost Accounting: A Managerial Emphasis, $9^{\text {th }}$ edition, Prentice Hall, New Jersey.

21. Hudson, Tania (1995), The Quality Question, AusIndustry, July/August, pp.14-15.

22. Ishikawa, Kaoru (1985), What is Total Quality Control? The Japanese Way, Engglewood Cliffs, N. J. Prentice-Hall.

23. John, H., Gregory, H., Barry, M., Richard, B. and William W., (1991), Current Trends in Cost of Quality, National Association of Accountants

24. Juran, J. M. (1985), The Quality Edge: A Management Tool, CIMA, London.

25. Juran, J. M., and Gryna, F. M. (1993), Quality Planning and Analysis, McGraw-Hill, New York.

26. Juran, J. M. (1995), Managerial Breakthrough-the classic book in improving management performance, McGraw-Hill, New York.

27. Kaplan, R. (1983), "Measuring Manufacturing Performance", The Accounting Review, 63, no.4, October, p.690.

28. Morse, W. J., H. Roth and K. M. Poston (1987), Measuring, planning and controlling quality costs (Montvale, NJ, National Association of Accountants, p.8).

29. Morse, W. J and Poston, K.M., (1993), Accounting for Quality Costs in CIM, Journal of Cost Management, Fall.

30. Morse W.J., and Roth, H.P. (1987), Why Quality Costs are Important, Management Accounting, Nov. 1987, pp. 42-43.

31. Ostrega, M. R. (1991), Return on Investment Through Costs of Quality, Journal of Cost Management, Summer, pp.37-44.

32. Plunkett, J.J. and B.G. Dale (1984), A Study of Audits, Inspection and Quality Costs in the Pressure Vessel Fabrication Sector of the Plant Industry, Proceedings of the Institute of Mechanical Engineers, Vol. 198B, No.2, pp.45-53.

33. Ponemon, L.A., (1990), Accounting For Quality Costs, Journal of Cost Management, Fall pp.44-47.

34. Qu, Wen and Judy Oliver, (1997), An Empirical Investigation into Quality Certification and Cost of Quality Reporting In Australian Manufacturing Organizations, A paper presented at the Asian Network of Schools of Accounting Conference, Melbourne, Australia, 4-5 April.

35. Rayner, P. and Porter, L.J, (1991), BS 5750/ISO9000-the Experience of Small and Medium-sized Firms, International Journal of Quality Reliability Management, Vol.8, No. 6, pp. 16-28.

36. Ross, G. (1990), The Revolution in Management Control, CMA Magazine, October, pp. 8-13.

37. Ross, P. (1993), The Impact of Total Quality Management Systems on Existing Management Accounting, University of Western Sydney, Working Paper. 
38. Ross P. (1995), Cost of Quality Reporting Practices by Australian Manufacturing Firms, Working Paper Series, Victoria University of Technology.

39. Ross P., M. Clear, K. Dixon, M. Bartlett, A. Johnson, B. Wheldon, and D. Hatcher, (1996), Total Quality Management Practices in the NSW Hospital System -An Overview, Australian Health Review, Vol. 19, No. 1, pp. 40-51

40. Roth, H. P. and Morse, W.J.(1983), "Let's help measure and report quality costs", Management Accounting, 55, no.2 (August), p.51.

41. Shank, J.K., and Govindarajan, Vigay (1989), Strategic Cost Management: New Wine or Just New Bottles?, Journal of Management Accounting Research, Fall, pp.47-65.

42. Shank, J.K., and Govindarajan, Vigay (1994), Measuring the "Cost of Quality" : A Strategic Cost Management Perspective, Journal of Cost Management, Summer pp. 5-17

43. Stanleigh, Michael, (1993), Accounting for Quality, Australian Accountant, Oct, pp.27-29.

44. Taguchi, G. (1986), Introduction to Quality Engineering, Asian Product Organisation, Tokyo, Japan.

45. Taguchi, G. and Clausing, D. (1990) Robust Quality, Harvard Business Review, Jan-Feb., pp.65-75.

46. Wheldon, Brett and Philip Ross (1998), Reporting Quality Costs: Improvement needed, Australian CPA, May.

47. Youde, R.K., (1992), Cost of Quality Reporting: How We See It, Management Accounting, January, pp. 3438. 